anaemia increased considerably with an exacerbation of diarrhoea. She was then given hog's desiccated gastric mucosa, and after one month's treatment the anaemia improved and the megalocytosis began to disappear. The administration of gastric mucosa was then stopped, but the condition of the blood still continued to improve, until five weeks later the anaemia had become of the hypochromic variety, and very few megalocytes were present.

These cases raise some points of interest. It is clear that in them either there was a deficiency in the intrinsic factor or the administration of the gastric mucosa coincided with an improvement in the absorptive power of the intestine, which ensured adequate absorption of the " haematinic principle." Evidence of the latter alternative is provided in the second case, because improvement continued after the administration of gastric mucosa ceased, although it is very unlikely that there were never periods in which the absorption improved during the nine months' administration of marmite. Evidence in favour of the former alternative is the fact that Castle and Rhoades state that in some cases of sprue there is a lack of intrinsic factor. Two other points may be stressed : first, that the administration of marmite does not necessarily cure the hyperchromic anaemia ; secondly, that the anaemia of coeliac disease may be a combined hyper- and hypo-chromic type-that is, may be due to deficiency in the " haematinic principle" and also in iron. Finally, it will be noted that the first case was given a 65 per cent. alcoholic extract of marmite in which both vitamin $\mathrm{B}$ and $\mathrm{B}_{2}$ are soluble, and further that Lucy Wills has shown that in marmite the "haemopoietic factor, whatever its nature may be, is waterand alcohol-soluble and heat-stable." It cannot therefore be argued that this alcoholic extract was not potent.

\section{Bothriocephalus ANaemia}

This form of macrocytic anaemia is even more rare than the preceding, as only three cases have been described in children under the age of 10 years. ${ }^{18}$ The anaemia is due either to the diminished absorption of the "haematinic principle" as the result of the action of the worm in the intestinal mucosa or to the actual destruction by the worm of the principle itself.

The original observations which appear in this paper have been carried out in association with my colleagues at the Children's. Hospital, Birmingham, in particular with Dr. J. C. Hawksley and Dr. Carey Smallwood, to whom I am greatly indebted. I would also express my thanks to the Medical Research Council for generous grants in aid of our work.

\section{ReFerences}

1 Witts, L. J.: Lancet, 1932, i, 495.

${ }^{2}$ Weiner, W., and Kaznelson, P.: Folia Haematologica, 1926, xxxii, 233.

${ }^{3}$ Dameshek, W.: Journ. Amer. Med. Assoc., 1933, c, 540

4 Strauss, M. B., and Castle, W. B.: Lancet, 1932, ii, 111.

${ }^{5}$ Wills, L.: Ibid., 1923, i, 1283.

'Mackay, H. M. M.: Medical Research Council, Special Report Series No. 157.

'Allen, F. M. B.

'Wintrobe, M. M., and Beede, R. T.: Medicine, 1933, xii, 187.

- Sheldon, J. H.: British Medical Journal, 1932, ii, 869.

${ }^{10}$ Gladstone, S. A.: Amer. Journ. Dis. Child., 1932, xliv, 81.

"Shipley, P. G.: Diseases of Infancy and Childhood (L. G. Parsons and S. G. Barling), London, 1933, p. 325.

${ }^{12}$ Elvehjem, C. A., and Sherman, N. I.: Journ. Biol. Chem., 1932, xcviii, 309 .

${ }^{13}$ Josephs, H.: Bull. Johns Hopkins Hosp., 1932, li, 185.

${ }^{14}$ Beard, H. H., and Myers, V. C.: Journ. Biol. Chem., 1931, xciv, 71

${ }^{15}$ Görter, E., Grendel, F., and Weyers, W. A. M.: Rév. franc. de Péd., 1931, vii, 747.

${ }^{16}$ Weill, L., and Mouriquand, C.: Congrès franc. de Méd., 1922

${ }^{17}$ Bennett, I., Hunter, D., and Vaughan, J.: Quart. Journ. Med. 1932, i (N.S.), 603 .

${ }^{18}$ Birkeland, T. W.: Medicine, 1932, xi, 1.

${ }^{19}$ Parsons, L. G., Hawksley, J. C., and Gittins, R.: Arch. Dis. Child., 1933, viii, 159

${ }^{20}$ Parsons, L. G., and Hawksley, J. C.: Ibid., 1933, viii, 117.

${ }^{21}$ Peabody, F. W.: Amer. Journ. Pathol., 1927, iii, 179.

\section{ANAESTHETICS FROM THE PRACTICAL AND SCIENTIFIC ASPECTS*}

BY

F. J. MORRIN, M.CH. N.U.I., B.A.O.,

SURGEON, JERVIS STREET HOSPITAL ; EXTERN SURGEON, ST. VINCENT'S HOSPITAL, DUBLIN

The nineteenth century dawned on a Europe disturbed by political intrigue, torn by dissension, and menaced by the despot:sm of Napoleon. Nations were busy with war and the preparations for further wars. Such conditions were not favourable to the pursuit of scientific knowledge, nor could suitable soil for the germination of scientific ideas have existed among students more interested in the campaigns of Alexander, Wellington, or Blucher than in the drudgery of laboratory investigation. Yet the twilight of the same century revealed an unexampled advance in science, invention, and social progress, while the contributions made to human welfare by our profession have not been surpassed in variety by the work of any other age. Among the many important discoveries which mark this great period two alonethe discovery of anaesthesia and the development of antisepsis-have raarked it as an epoch in the history of mankind. This period witnessed the commencement of scientific investigation into anaesthetic agents, and, fortunately for our profession, it produced distinguished physicists capable of analysing them. That anaesthesia was known prior to this time is, however, undoubted, but for some extraordinary reason the mediaeval substitutes were little, if at all, employed after the middle of the seventeenth century. It seems inexplicable that such knowledge should have died out, but it is certain that Paré and Wiseman in the latter half of the seventeenth century did not employ it.

\section{Historical}

The idea of producing sleep to perform surgical operations dates back to remote antiquity. In Genesis ii, 21, we read: "The Lord caused a deep sleep to fall upon Adam, and he slept: and He took one of his ribs, and closed up the flesh instead thereof." The use of a soporific potion as a substitute for anaesthesia was first described by Dioscorides, the father of materia medica, who was a Greek surgeon in Nero's armies (A.D. 54-68). He recommended mandragora wine as a soporific in surgical operations or cauterizations, either per os, as a clyster, or as an inhalation. He also made a distinction between its soporific effect and its anaesthet:c effect. The name of Teodorico, the most original surgeon of antiquity, is associated with the soporific sponge wh:ch was in common use by his father, Hugh of Lucca. This sponge was steeped in a mixture of opium, hyoscyamus, mulberry. juice, lettuce, hemlock, ivy, and mandragora, then dried, and, when moistened, was inhaled by the patient, who was awakened by applying fennel juice to the nostrils. Mandragora, as an anaesthetic substance, appears to have been in general use throughout the Middle Ages. From the soothing Egyptian nepenthe of the Odyssey, which Helen cast into the wine for Ulysses, to the Samme de Shinta of the Talmud, the bhang of the Arabian Nights, or the "drowsy syrups " of Shakespeare, we may infer that the practice of drugging to produce insensibility to pain was common usage, while it is said that trephining is still practised among the Bolivian and Peruvian natives and that coca leaves (Erythroxylon coca) are chewed to produce amnesia. There is no definite record of the

* Read in opening a discussion in the Section of Pharmacology and Therapeutics at the Annual Meeting of the British Medical Association, Dublin, 1933. 
use of anaesthesia in ancient Ireland, but one of the manuscripts of the Royal Irish Academy is a Celtic materia medica of the twelfth century, and in this is an account of mandragora and its properties, apparently copied from Pliny.

\section{Ether and ChLoroform}

The history of the introduction of ether anaesthesia has been the source of bitter controversy, but the first reported case occurred on October 16th, 1846, when William T. Green Morton, a Massachusetts dentist, painlessly removed the aching bicuspid tooth of one Eben Frost of the same town. The anaesthetic was taken up by Drs. Warren and Bigelow, and an account of it published on November 18th, 1846, in the Boston Medical and Surgical Journal. Less than two months later the anaesthetic was employed in Dublin. On January 1st, 1847, Mary Kane of Drogheda, 18 years of age, had her arm amputated in the m:ddle third for an injury of the elbowjoint. The surgeon, Dr. McDonnell of the Richmond Hospital, submitted himself five or six times to the induction of ether anaesthesia before allowing his patient to undergo the risk.

For the discovery of chloroform we are also.indebted to an American-Guthrie of Massachusetts-but Sir John Simpson of Edinburgh is credited with having performed the first operation under chloroform on November 15th, 1847, although he had used ether since its introduction in the previous January. Chloroform rapidly grew in public favour, and in a short time was practically the only anaesthetic employed. It was used with reckless disregard of precautions, in enormous quantities, on handkerchiefs or towels, and by anybody who happened to be handy. Very soon death from chloroform became as common a heading in the papers as fatal accidents following a Bank Holiday are to-day. In a very short time-mainly as a result of coroners' comments-the use of chloroform was superseded by ether. Despite its apparent safety, deaths were frequent owing to its indiscriminate and unskilful administration, and antidotes to ether vapour were a common topic in the journals.

The effect of the introduction of these anaesthetic agents to the surgical branch of our profession needs little comment. The surgical conjurer, who performed operations with lightning speed against the clock, gave place to the deliberate aseptic operator who regarded the tissues as living things and to whom aseptic, atraumatic surgery represented the ideal. That ether has maintained its place as the safest anaesthetic agent cannot be denied. Administered daily by more untrained than trained operators in all varieties of cases, it has upheld its reputation for safety, while statistics show that the immediate mortality from its use is surprisingly low. Of recent years, however, there has been a movement towards something better. The most ardent advocates of ether anaesthesia cannot deny its disadvantages. Despite skilful administration it is an unpleasant ordeal for the patient. It is the general experience that a patient who has to undergo a subsequent operation fears the anaiesthetic more than the operation. The terror of a child undergoing ether anaesthesia is reflected in its desperate struggles, and I have frequently s:ghed for the soporific sponge of Teodorico when watching a resident surgeon assisted by the theatre staff endeavouring to subdue a burly labourer. That ether has a high morbidity rate, as distinct from its mortality rate, I am convinced. The incidence of post-operative bronchitis or atelectas:s is undoubtedly higher with it than with any other form of anaesthesia, while, when the pulmonary complication proves fatal, the mortality is ascribed to pneumonia and not to the anaesthetic.

\section{BASAL NARCOTICS}

Hitherto various measures for overcoming the disadvantages of induction have been only partially satisfactory. Inasmuch as they did little to minimize the patient's ordeal and nothing to reduce the volume of ether vapour required to produce surgical anaesthesia the value of their employment was reduced. The recent developments in the field of basal anaesthes:a mark a very great stride forward, although it represents practically the only noteworthy advance since the introduction of the Clover inhaler in 1876. The pre-operative amnesia is of immense psychological benefit to the patient. The amount of inhalation anaesthetic is considerably diminished, a point of great importance since the incidence and severity of post-operative bronchitis in predisposed patients appears to bear a direct relation to the quantity of ether used. The prolonged period of post-operative sleep, by minimizing pain, reducing nausea, and eliminating restlessness, favours post-operative healing, a point of importance in abdominal cases.

The list of basal narcotics is becoming daily largier. Paraldehyde, avertin, nembutal, sodium amytal, sodium soneryl, and pernocton, each has its advocates. Dogmatic assertions as to the non-toxicity and safety of these drugs cannot yet be made ; the question of individual idiosyncrasy must always be considered, and the danger of the barbiturates in hepatic disease cannot be disregarded.

Many anaesthetists consider the prolonged period of post-operative sleep obtained with most of the basal narcotics undesirable, and in certain subjects or in operations of a minor character this may be an admitted disadvantage. The introduction of sodium evipan shows a tendency to eliminate this drawback. So far animal experiments and clinical use indicate for this drug very low toxicity, high therapeutic effect, and rapid detoxication. The duration of anaesthesia is about fifteen to twenty minutes, and consequently its employment as a general anaesthetic is limited. It must be considered not as a basal narcotic, but as a general anaesthetic. For a short period, which varies in different individuals, the patient is anaesthetized to the point of full muscular relaxation. If inhalation anaesthesia is required it is necessary to ensure that the patient has recovered from this deep anaesthetic period. The duration of anaesthesia may permit the performance of an uncomplicated appendicectomy or herniotomy (in one personal case Caesarean section was performed), but it cannot be recommended if the operation is likely to last more than fifteen minutes. Recovery follows without unpleasant after-effects, and I believe extended experience will prove it a most valuable adjunct to the surgeon. From a limited experience of nembutal, I am impressed by its dramatic efficiency. Given to healthy subjects it is well tolerated, and accidents should not occur. I feel, however, that it is not a drug that one should employ when dealing with a bad anaesthetic risk, such as the patient suffering from a severe infection or toxaemia. Amongst the bad risks I should place the advanced cases of toxic goitre, the patient with advanced renal disease, the prostatic patient with chronic urinary obstruction, and the patient with intestinal obstruction or jaundice. I feel that to use nembutal in such cases is to place the extra load on the patient's eliminatory system which may contribute to an unfortunate result.

My personal preference for a basal narcotic remains with avertin. The rectal administration is, however, inconvenient. Though rapidly absorbed, the anaesthesia can be controlled to a certain extent by washing out the rectum within thirty minutes of its administration. I have been in the habit of giving large doses of luminal pre-operatively for some time. It is a method which 
is extremely convenient. Luminal 10 to 15 grains, administered per os two or two and a half hours pre-operatively, produces a quiet sleep and diminishes pre-operative excitement, while in vigorous athletic patients I have frequently given 20 to 25 grains prior to an upper abdominal operation, and found it safe, convenient, and efficient.

A practice which has appeared recently is the employment of a basal narcotic with a patient who is receiving a spinal anaesthetic. This $I$ feel is a method meriting condemnation. ' It is generally observed that the blood pressure is reduced by most of those basal narcotics, although the reduction may only amount to 10 to $20 \mathrm{~mm}$. of mercury. With spinal anaesthesia, on the other hand, the blood pressure is usually markedly reduced; sometimes, despite precautions, the fall of pressure is rapid and profound. In those circumstances the addition of a basal narcotic will not improve matters, and may be sufficient to jeopardize the patient's safety. Moreover, when employing spinal anaesthesia to obtain a high abdominal anaesthetic effect, the action of the lower intercostal and abdominal muscles as accessory respiratory muscles is abolished, while the phrenic centre in the cord may be encroached upon, and it is not unusual to notice somnolence and shallow respiratory interchange when the anaesthesia has spread a little too high. The depressant effect of a basal narcotic on the respiratory centre in such cases appears likely to cause some anxious moments.

\section{Spinal Anaesthesta}

The use of spinal anaesthesia has become increasingly popular in recent years, and undoubtedly a satisfactory spinal anaesthetic is the perfect anaesthetic for the surgeon. Some patients do not regard the maintenance of consciousness as an advantage, though, when it is used continually in hospital wards, a great number of patients show a preference for it. By no other method is such perfect abdominal relaxation obtained, ensuring satisfactory surgical exposure, avoidance of rough handling, accurate apposition by suture, and facile operative technique. Amongst the cifferent drugs employed, perhaps personal experience is of more value than any elaboration of technical methods. With perfectly sharp, well-fitting needles and syringe, and a spine well flexed in the median line, the number of blind punctures and unsatisfactory spinal anaesthetics is reduced to a minimum. My own experience is practically confined to two cirugs-novocain and percaine.

Novocain 5 per cent. solution, in doses of 10 to $12 \mathrm{mg}$., has proved in my hands the most reliable for producing anaesthesia below the umbilicus. When confined to this lim:t I regard it as perfectly safe, and if combined with ephedrine and the lowered head position it is seldom associated with unpleasant effects. For high abdominal anaesthesia I have occasionally experienced a marked fall of blood pressure, with nausea, vomiting, and collapse -symptoms which are unsettling, and certainly alarming to onlookers not accustomed to the procedure. Spinal anaesthesia, employing the diluted solution of percaine 1 in 1,500 , appears to have advantages over novocain when used for high abdominal anaesthesia. The fall of blood pressure is very much less, and unpleasant effects are less common. The method recommended by Jones brings upper abdominal surgery within the scope of satisfactory spinal anaesthesia. My enthusiasm for the method was unfortunately damped by a fatality following the injection of $17 \mathrm{c.cm}$. between the second and third lumbar spines in a robust woman of 36 with cholelithiasis ; while I have seen a fatality occur in an elderly man, with a strangulated hernia of fifty-six hours' duration, following the injection of a buffered solution of percaine between the third and the fourth space, the patient succumbing twenty minutes after completion of the operation. Percaine is extremely toxic if absorbed into the circulation, and there may be individual idiosyncrasy to the drug. If bleeding occurs following puncture it is wiser not to proceed, and I do not give more than $15 \mathrm{c.cm}$. of the 1 in 1,500 solution-and that between the second and the third space-for upper abdominal operations. If the anaesthesia is inadequate it may be supplemented by splanchnic anaesthesia or mesenteric infiltration.

A disadvantage of spinal administration is the inab:lity to localize the level of anaesthesia consistently. It may be unduly high, perhaps to the nipple line, when performing a hernia, while using a similar technique in the following case the anaesthetic may be barely sufficient for the operation. The post-operative headache, sometimes associated with nausea and dizziness, which occasionally follows spinal anaesthes:a constitutes one of its greatest drawbacks. Such headaches may follow lumbar puncture alone. It occurs most frequently in anaemic patients, and may be obviated by keeping the patient in the head-down position for twenty-four hours following the operation. When it does oscur nothing seems to give such relief as an intravenous injection of 15 to 20 per cent. saline solution.

A discussion of local anaesthesia is perhaps more a subject for a surgical meeting than for this Section, since the induction of the anaesthetic becomes part of the technique of the operation. The most valuable application of this method is in the operation of thyroidectomy, while its employment in the reduction and treatment of fractures is rapidly superseding all other methods of anaesthesia.

\section{"The Perfect Anaesthetic"}

The increasing number of methods indicates that room for improvement exists in our present methods of anaesthesia. Further surgical progress can be accomplished if the anaesthetist can provide safe anaesthesia for the bad risks. Patients will submit more readily to surgical treatment when anaesthesia can be induced with safety in the amnesic patient. Good operative work depends on the complete muscular relaxation and normal respiratory rhythm of the perfectly anaesthetized patient, and satisfactory convalescence depends on freedom from postanaesthetic morbidity. The necessity for the trained anaesthetist is more urgent than ever: the casual anaesthetist is the patient's nightmare and the surgeon's purgatory. The trained man is an essential unit in the modern surgical hospital.

Before concluding, may I suggest the requirements of a perfect anaesthetic agent? I submit that:

Administration should be accomplished without discomfort to either the young or the old patient, and without complicated apparatus.

Induction must be agreeable, and the anaesthetic should not have any deleterious effect on the respiration or circulation.

Blood pressure should be ma:ntained at a normal level throughout.

Elimination should be rapid without producing harmful effects on the hepatic, renal, or pulmonary tissue.

The anaesthetic effect should be induced gradually, and it should be at all times under control.

In addition to securing sensory paralysis, complete muscular relaxation should be rapidly and safely obtained.

Judged by these standards the perfect anaesthet:c awaits discovery. Of recent years extensive developments in the technique of anaesthesia have taken place. Improved methods of administration have been accompanied by the introduction of ingenious apparatus, and-perhaps on this account-the anaesthetist has welcomed the products of the analytical chemist with faith and hope, while the surgeon has extended to him the greatest of all virtues-charity. 